\title{
Fecal steroid analysis for monitoring reproduction in the sun bear (Helarctos malayanus)
}

\author{
Franz Schwarzenberger ${ }^{\mathrm{a}, *}$, Gabriella Fredriksson ${ }^{\mathrm{b}}$, \\ Karl Schaller ${ }^{c}$, Lydia Kolter ${ }^{\mathrm{d}}$ \\ ${ }^{a}$ Department of Natural Sciences, Institute of Biochemistry, University of Veterinary Medicine, \\ Vet. platz 1, A-1210 Vienna, Austria \\ ${ }^{\mathrm{b}}$ Institute for Biodiversity and Ecosystem Dynamics, University of Amsterdam, \\ PO Box 94766, NL-1090 GT Amsterdam, The Netherlands \\ 'Allwetterzoo Münster, Sentruper Str. 315, D-48161 Münster, Germany \\ ${ }^{\mathrm{d} Z o o}$ Köln, Riehler Str. 173, D-50735 Cologne, Germany
}

Received 16 November 2003; received in revised form 18 February 2004; accepted 18 March 2004

\begin{abstract}
Fecal steroid analyses were conducted on captive $(n=10)$ and free-ranging $(n=2)$ sun bears (Helarctos malayanus) in order to establish a noninvasive technique for monitoring endocrine profiles during the estrous cycle and pregnancy. Secondly, the effect of the contraceptive porcine zona pellucida protein (PZP) on reproductive function was studied. Finally, we investigated whether the sun bear, naturally living in the aseasonal tropical forests of Southeast Asia, is a seasonal breeder. Fecal samples were collected over periods of 7-48 months in captive untreated $(n=8)$ and PZP-treated $(n=2)$ female sun bears. In addition samples were collected over a period of 12 months from radio-collared free-ranging females $(n=2)$ in their natural habitat in Indonesian Borneo. Androgens, precursors of estrogens, were found to be reliable indicators of the follicular phase, whereas estrogens were found unsuitable. Pregnanediol assay was found to be a reliable indicator of luteal function. Results indicate that sun bears are polyestrous, nonseasonal breeders. Interestrus intervals in nonpregnant animals $(n=2)$, which were monitored for 27 months, were between 140 and 216 days. Luteal phases (89.6 \pm 3.7 days; $n=9)$ were preceded by androgen peaks of $15.2 \pm 1.0$ days $(n=10)$. Hormonal profiles of two females treated with PZP indicated missing ovarian activity in one, and persistent follicular and luteal activity in another animal. However, extended periods of missing ovarian, and persistent follicular and luteal activity were also observed in other sun bears studied.
\end{abstract}

(C) 2004 Elsevier Inc. All rights reserved.

Keywords: Ursidae; Reproductive physiology; Estrous cycle; Porcine zona pellucida protein; Fecal steroid analysis; Seasonality

\footnotetext{
*Corresponding author. Tel.: +43-1-250774104; fax: +43-1-250774190.

E-mail address: Franz.Schwarzenberger@vu-wien.ac.at (F. Schwarzenberger).
} 


\section{Introduction}

The sun bear, Helarctos malayanus, is the smallest species in the ursine family (adult weight $27-65 \mathrm{~kg}$ ) and inhabits tropical rainforests of Southeast Asia; its distribution ranges from the eastern edge of India, through Myanmar, Lao-PDR, Cambodia, Vietnam, Thailand, Malaysia to the islands of Sumatra and Borneo. Although no reliable data concerning sun bear population numbers are available, the species is threatened by large-scale habitat destruction and poaching [1,2]. Information about sun bear social organization and reproductive behavior in the wild is limited. In captivity, cubs are born throughout the year and litters usually consist of one cub [3-5]. Only one twin pair among 57 surviving offspring in European zoos has been observed [4]. The gestation period in zoos were reported to be 95-107 days, and, according to studbook data, the inter-birth interval of sun bears, in which cubs died after parturition, is only $126 \pm 9$ days, suggesting there was no delayed implantation $[3,4]$. In the wild, cubs most likely remain with their mothers until they are fully grown ( $\sim 2$ years), as reported for other ursid species [1,2].

The current population of sun bears in European and American Zoos is about 50 and 60 animals, respectively [4]. The captive population has been declining since 1990, but it is considered at carrying capacity as several institutions decided to stop keeping sun bears. More than half of the 16 cubs born in the European population during the last decade are still in their natal group. Consequently, a method of contraception has been deemed necessary. The successful use of porcine zona pellucida protein (PZP) in ungulate and carnivore species [6] has encouraged the zoos of Cologne (Germany) and Romaneche (France) to test this contraceptive on sun bears.

The objectives of this study are three-fold. Firstly, we wanted to establish a noninvasive technique for monitoring endocrine profiles during estrous cycle and pregnancy in sun bears. Secondly, we wanted to monitor the effect of the contraceptive PZP on endocrine ovarian function. And thirdly, we wanted to investigate whether sun bear reproduction is seasonal.

\section{Materials and methods}

\subsection{Animals and sample collection}

The female sun bears $(n=12)$ included in this study are listed in Table 1. Females kept in zoos were housed together with males, except for the PZP-treated animal Bärlein from Cologne zoo, which was without a male contact between August 1996 and November 1997. Group compositions (male-female) were: Basle Zoo 1.2; Cologne Zoo 1.3; Frankfurt Zoo 1.1; Jihlava Zoo 1.1; Münster Zoo 1.4; Romaneche Touroparc 1.3. Females in the groups in Cologne Zoo, Münster Zoo, and Romaneche Touroparc were related animals. The other study animals were unrelated to members of their own group. The captive sun bears included in this study were sexually mature animals; their breeding history and ages at the onset of this study are listed in Table 1. The exact body weights of the captive animals were not known, but were estimated to be over $50 \mathrm{~kg}$ in each individual, and as such were higher than known body weights from sun bears in the wild [4].

The two free-ranging females in Indonesian Borneo were confiscated at different times and locations, and subsequently radio-collared and released at the study site; the two 
Table 1

Reproductive history of sun bears included in this study

\begin{tabular}{|c|c|c|c|c|c|}
\hline Location & $\begin{array}{l}\text { Animal (name } \\
\text { and studbook-ID) }\end{array}$ & $\begin{array}{l}\text { Age at the } \\
\text { beginning of } \\
\text { the study }\end{array}$ & $\begin{array}{l}\text { Periods of sample } \\
\text { collection }\end{array}$ & Breeding history & Results reported in this study \\
\hline Basle & Anak (\#112) & 18 & 8 months & \multicolumn{2}{|c|}{$\begin{array}{l}\text { Three cubs before this study wasErratic follicular and luteal activity } \\
\text { conducted }\end{array}$} \\
\hline Basle & Kawan (\#134) & 14 & 8 months & Nulli parous animal & Missing luteal activity \\
\hline Cologne & Bärlein (\#133) & 12 & 47 months & $\begin{array}{l}\text { Five cubs before this study } \\
\text { was conducted (of these the } \\
\text { last cubs were the twins Bali } \\
\text { and Bao included in this study) }\end{array}$ & $\begin{array}{l}\text { PZP: September 1994, October } 1994 \text {, } \\
\text { June 1995, and February 1996; monitoring } \\
\text { started in January 1995. Missing luteal } \\
\text { activity for } 3.5 \text { years after PZP treatment; } \\
\text { one estrous cycle at end of study }\end{array}$ \\
\hline Cologne & Bali (\#193) & & $\begin{array}{l}15 \text { months }+3 \text { months } \\
\text { during pregnancy }\end{array}$ & Primiparous during this study & $\begin{array}{l}\text { Estrous cycle; pregnant one year after } \\
\text { that period }\end{array}$ \\
\hline Cologne & Bao (\#192) & & $\begin{array}{l}10 \text { months }+3 \text { months } \\
\text { during pregnancy }\end{array}$ & Primiparous during this study & $\begin{array}{l}\text { Missing ovarian activity for } 10 \text { months; } \\
\text { pregnant one year after that period }\end{array}$ \\
\hline Frankfurt & Lotyinka (\#167) & 14 & 7 months & Nulli parous animal & Missing luteal activity \\
\hline Jihlava & $\mathrm{Li}(\# 176)$ & 14 & 8 months & Nulli parous animal & Missing luteal activity \\
\hline Münster & Sichel (\#79) & 22 & 27 months & $\begin{array}{l}\text { Three cubs before this study } \\
\text { was conducted (one of these } \\
\text { is the animal Mali) }\end{array}$ & Estrous cycles \\
\hline Münster & Mali (\#132) & 13 & 27 months & $\begin{array}{l}\text { One cub before this study } \\
\text { was conducted }\end{array}$ & Estrous cycles \\
\hline Romaneche & Ours (\#130) & 16 & 8 months & $\begin{array}{l}\text { Two cubs before this study } \\
\text { was conducted }\end{array}$ & $\begin{array}{l}\text { PZP: July 1995, August } 1995 \text {, } \\
\text { November 1995, June 1996, and } \\
\text { August 1997; monitoring started in } \\
\text { February 1997. Erratic follicular } \\
\text { and luteal activity }\end{array}$ \\
\hline \multicolumn{6}{|c|}{ Free-ranging animals } \\
\hline Indonesia & Ganja & 3 & 13 months & Nulli parous animal & $\begin{array}{l}\text { Follicular activity, not followed by } \\
\text { luteal activity }\end{array}$ \\
\hline Indonesia & Ucil & 3 & 13 months & Nulli parous animal & Missing ovarian activity \\
\hline
\end{tabular}


females were unrelated. These free-ranging animals were about 3 years at the onset of this study and it is possible that they were only reaching sexual maturity.

Freshly defecated fecal samples were collected over periods of 7-48 months. Samples were collected one to three times per week; sampling frequency was increased up to six samples per week during periods of estrus. Estrus was determined by opportunistic observations made by the animal keepers. In most cases estrus was detected by mating. There were only a few other behavioral correlates of estrus, which did not occur in each animal, i.e. rubbing of the vulva, prolonged close proximity to the male, aggressiveness towards females in the group. Behavioral estrous varied in lengths inter- and intraindividually between 1 and 11 days.

Samples from zoo animals were collected after observed defecation or after identifying feces by the green marker dye chromium III oxide, which was fed in order to color the feces of the study animals. Samples collected at the zoos were stored frozen at $-20{ }^{\circ} \mathrm{C}$. Samples from the wild were also collected after observed defecation from the two free-ranging radio-collared females. Samples collected in the field were stored in 95\% alcohol.

Additionally, ad libitum observations of wild sun bears were made in East Kalimantan (Indonesian Borneo) and birth dates calculated for natural habitat. For these calculations, the size of the wild cubs were estimated and correlated with growth curves of confiscated cubs. During a period of 25 months a total of 18 birth dates could be determined with reasonable certainty.

\subsection{Treatment with porcine zona pellucida protein $(P Z P)$}

Two female sun bears were treated with the contraceptive PZP, according to protocols by Dr. J.F. Kirkpatrick (Billings, Montana) who provided the PZP. The dose was $65 \mu \mathrm{g}$ for each intramuscular injection. Times of treatment in relation to this study and treatment intervals are given in Table 1. Initial treatment was given with complete Freund adjuvant, whereas incomplete Freund adjuvant was used for booster injections.

\subsection{Extraction of fecal samples and enzyme-immunoassays}

Feces were extracted with methanol; briefly fresh feces $(0.5 \mathrm{~g})$ were mixed with $0.5 \mathrm{ml}$ of distilled water and $4 \mathrm{ml}$ of methanol, and subsequently mixed and vortexed with $3.0 \mathrm{ml}$ petroleum ether as described and used for several other species [7]. Feces collected from the wild was lyophilized before extraction. The water content of feces is about $80 \%$. Therefore, lyophilization increases fecal steroid concentrations about four- to five-fold. Except for differences in the concentration, results are comparable as fluid removal from the feces does not effectively alter steroid profiles, and, as it was found that concentrations between frozen and lyophilized fecal samples are highly correlated [7].

The methanol fraction from the extract was diluted and analyzed using group-specific enzyme-immunoassays (EIA) [7,8]. In a preliminary set of samples, EIAs for immunoreactive progesterone, androgen and estrogen metabolites were tested for their ability to detect follicular and luteal phases. Briefly, group-specific antibodies were raised in rabbits and assays included 20-oxo-pregnanes (antibody: 5 $\alpha$-pregnane-3 $\beta$-ol-20-one 3HS:BSA; progesterone crossreactivity in this assay is $100 \%), 20 \alpha-\mathrm{OH}$-pregnanes (5 $\beta$-pregnane- $3 \alpha-$ 
20 $\alpha$-diol 3HS:BSA; trivial name pregnanediol), 17-oxo-androgens (5 $\alpha$-androstane-3,17dione 3-CMO:BSA; trivial name epiandrosterone), and total estrogens (estradiol-17 $\beta-\mathrm{OH}$ 17HS:BSA). Intra- and inter-assay coefficients of variation of these assays were between 10 and $15 \%$ [8].

\subsection{Data analysis}

Definition of the anestrous period, the follicular (FP) and luteal phases (LP) of the reproductive cycle were based on the analysis of fecal 17-oxo-androgens and $20 \alpha-\mathrm{OH}-$ pregnanes, respectively. As samples were not collected every day, the interval between two consecutive values was divided by two and resulting values added to the FP and the LP, respectively. Data in the results are presented as mean \pm S.E.M.

Calculations for definitions of the FP and LP were made from wet feces collected from captive animals. Firstly, LP was defined as the period when $20 \alpha-\mathrm{OH}$-pregnanes had increased and remained at $>150 \mathrm{ng} / \mathrm{g}$ feces. Secondly, mean values of all $20 \alpha-\mathrm{OH}$-pregnanes below $150 \mathrm{ng} / \mathrm{g}$ were calculated. This resulted in $63.4 \pm 96.0 \mathrm{ng} / \mathrm{g}$ (mean \pm S.D.). From this a new threshold for LP was calculated. We defined the LP when $20 \alpha-\mathrm{OH}-$ pregnanes concentrations were three standard deviations above the mean. This resulted in $351.4 \mathrm{ng} / \mathrm{g}$ and the new threshold was set at $350 \mathrm{ng} / \mathrm{g}$ for final calculations of the onset and the end of the LP. Subsequently, the mean for the 17-oxo-androgen values during the LP were calculated and used to define the threshold for the definition of the FP. The 17-oxo-androgens concentrations during LP were $31.9 \pm 37.0 \mathrm{ng} / \mathrm{g}$ (mean \pm S.D.); from this the mean + three SD was calculated as $142.9 \mathrm{ng} / \mathrm{g}$. For further calculations a 17-oxo-androgen cut off value of $150 \mathrm{ng} / \mathrm{g}$ feces was used to define the FP. Accordingly, the final threshold for definitions of the anestrous period was set at $20 \alpha-\mathrm{OH}$-pregnane and 17-oxo-androgen values below 350 and $150 \mathrm{ng} / \mathrm{g}$ feces, respectively.

\section{Results}

\subsection{Determination of suitable assays}

In a preliminary study, four assays for the determination of progesterone, androgen, and estrogen metabolites were tested. Results for one reproductive cycle from the animal 'Sichel' are shown in Fig. 1. The assays for 17-oxo-androgen (epiandrosterone antibody) and for $20 \alpha-\mathrm{OH}$-pregnanes (pregnanediol antibody) were suitable for monitoring the follicular and the luteal phase, respectively. The androgen peak coincided with behavioral estrus and mating. Because estrogens and 20-oxo-pregnanes were unsuitable for estrous cycle monitoring, these assays were not used for further analysis.

\subsection{Reproductive pattern and seasonality}

\subsubsection{Captive animals}

In nonpregnant animals, estrous cycles $(n=9)$ consisting of a follicular phase followed by a luteal phase occurred in four animals (Sichel, Mali, Bali, Bärlein; Figs. 2, 3, and 6). 


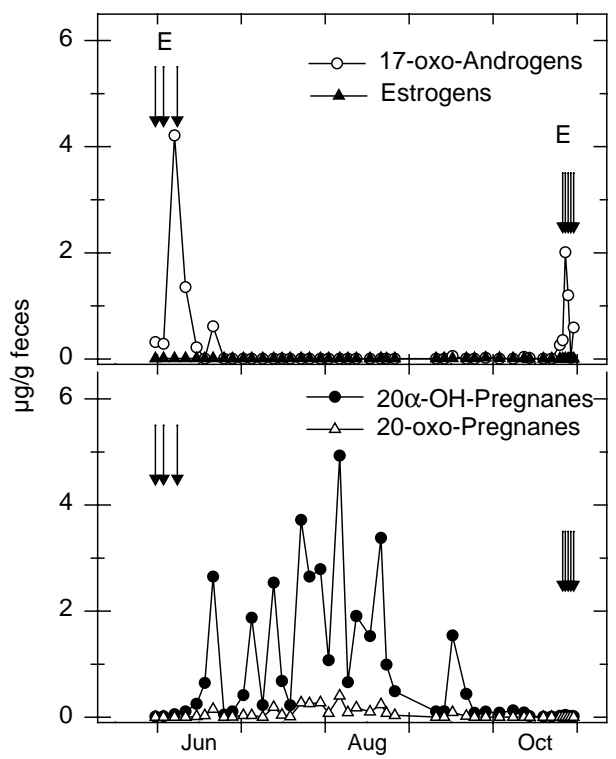

Fig. 1. Comparison of different assays for immunoreactive estrogen, androgen, and progesterone metabolites in fecal samples of the sun bear 'Sichel'. According to these results, 17-oxo-androgens and 20 $\alpha$-OH-pregnanes were analyzed in further samples and used as indicators of follicular and luteal periods of the estrous cycle, respectively. Estrus (E).

The calculations of the mean follicular and luteal phase lengths were based on fecal 17oxo-androgen and $20 \alpha-\mathrm{OH}$-pregnane concentrations, respectively. The FP and LP lengths of the sun bears in this study were $15.2 \pm 1.0$ (range: $8-21, n=10$ ) and $89.6 \pm 3.7$ (range: 74-111, $n=9$ ) days, respectively; FP of Bärlein (Fig. 6), that were not followed by a LP, were not included in this calculation. The $20 \alpha-\mathrm{OH}$-pregnane concentrations started to increase to LP values only about 10 days after 17-oxo-androgens had decreased to basal values at the end of the FP. Therefore the interval from the beginning of the follicular to the beginning of the luteal phase was longer (25.0 \pm 2.6 days; $n=9$; range $11-35$ days) than the calculated FP length.

The animals 'Sichel' and 'Mali' from Münster zoo exhibited several subsequent estrous cycles (Fig. 2). The estrus intervals of 'Sichel' were $\sim 145$ days $(n=3)$. Those of 'Mali' were 216 and 150 days, respectively. Follicular and luteal phases in both animals were missing for periods of over 6 months during the second year of study. During this time a period of behavioral estrus was observed in Mali, however, this estrus did not coincide with a parallel increase in fecal 17-oxo-androgen levels.

Fecal steroid levels in pregnant animals (Fig. 3) were comparable to those during estrous cycles in nonpregnant animals. However, $20 \alpha-\mathrm{OH}$-pregnane levels in the pregnant female 'Bali' increased to LP levels approximately one month after conception (Fig. 3a) and decreased to levels below $500 \mathrm{ng} / \mathrm{g}$ feces 2 weeks before parturition.

Missing follicular and luteal activity for periods of 7-10 months was observed in four captive animals (Fig. 4). Of these, 'Li' had a follicular period of 20 days, which was not 


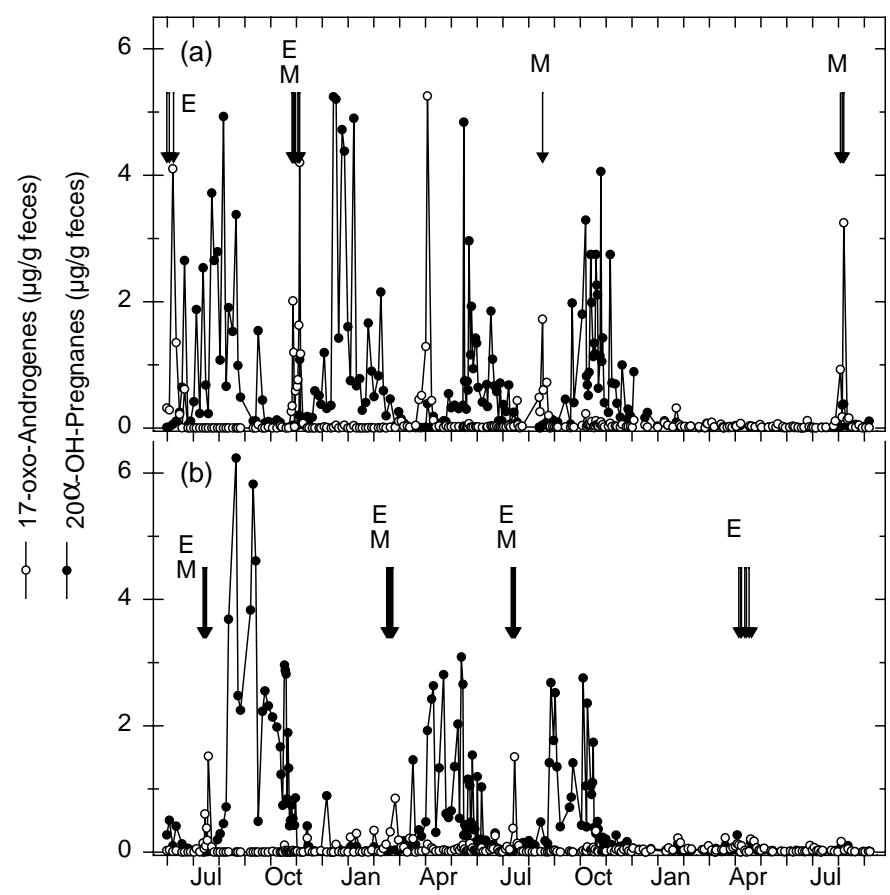

Fig. 2. Concentrations of 17-oxo-androgens and 20 $\alpha$-OH-pregnanes in fecal samples of female sun bears ((a) 'Sichel'; (b) 'Mali') with regular estrous cycles. Estrus (E); mating (M).

followed by a luteal phase. 'Bao' was acyclic for 10 months in 1998, but had a normal pregnancy in 2000 .

\subsubsection{Free-ranging bears}

Fecal steroid concentrations in two radio-collared, free-ranging sun bears were measured in lyophilized fecal samples, and thus concentrations were about four to five times higher than those found in the wet feces of the captive animals. Elevated estrogen precursors were observed twice during the period of 1 year in the female 'Ganja' (Fig. 5b). These follicular periods lasted about one month, but consisted of two periods of elevated steroid levels of about 8 and 20 days, each. Periods of elevated estrogen precursors were not followed by subsequent elevations in fecal progesterone metabolites. The peak in December coincided with externally swollen and pink genitalia as well as estrus behavior (rubbing of genitalia on logs, sluggishness). The first follicular peak coincided with the driest period of the year, whereas the second occurred during the wet season. The animal 'Ucil' showed two minor rises in estrogen levels during the same 12-month period.

\subsubsection{Reproduction of wild sun bears in East Kalimantan}

During a period of 25 months in the forest in East Kalimantan (Indonesian Borneo), 62 independent observations of wild bears were made, out of which 19 observations involved 


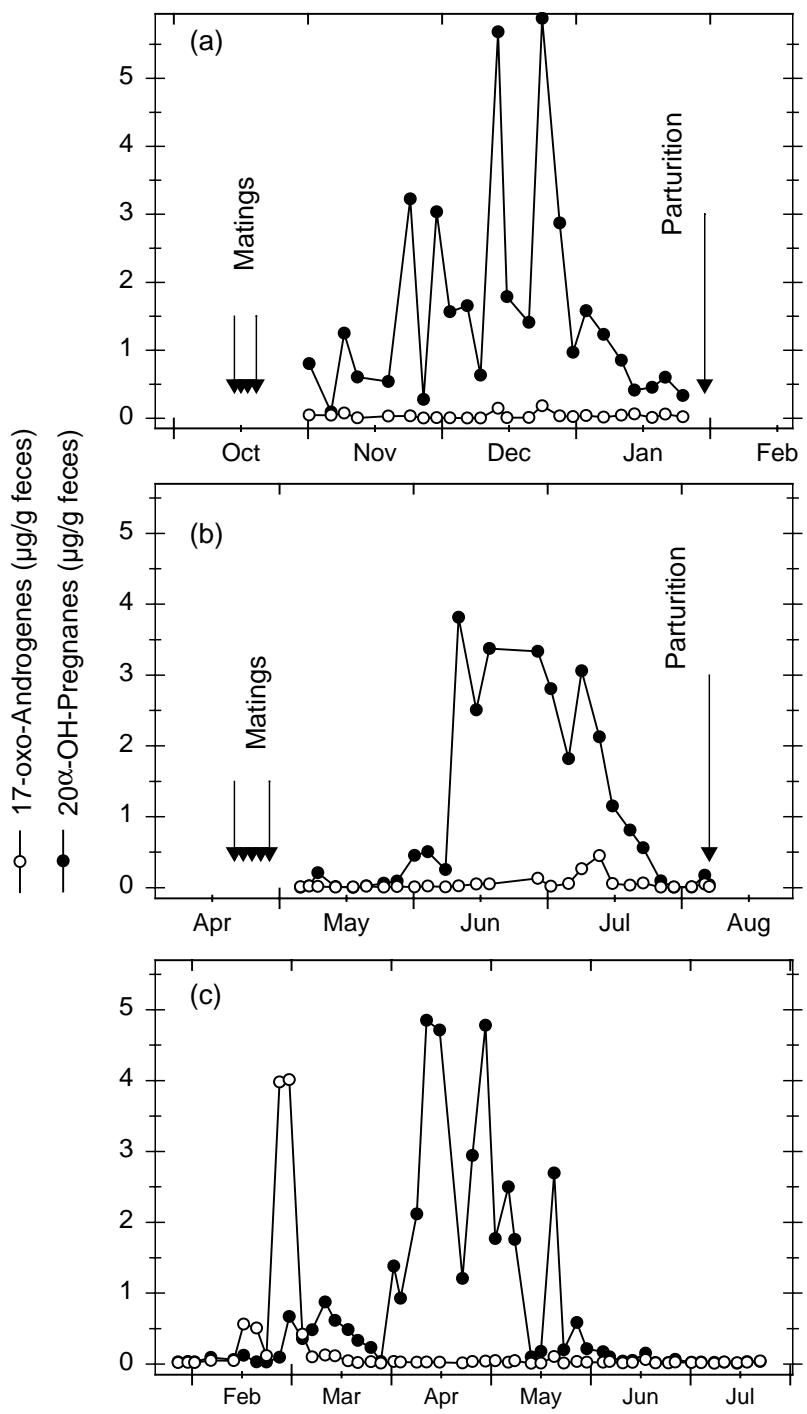

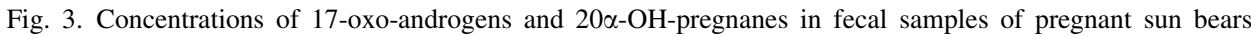
((a) 'Bali'; (b) 'Bao'); conceptions in both animals occurred after several matings during periods indicated in the graphs. For comparison, the hormone profiles during the estrous cycle of Bali (c) are shown in the bottom panel.

two or more bears. A total of 18 birth dates could be determined from the wild with reasonable certainty, including data from newly born cubs confiscated by wildlife authorities, and newly born cubs encountered in logs. This resulted in cubs being born in 15 out of 25 months between May 1997 and May 1999. The first year (1997) was an El Nino year when rainfall patterns were 'abnormal' and there was a drought for more than a year. Although rainfall patterns are not consistent on an annual basis, a distinction could be 


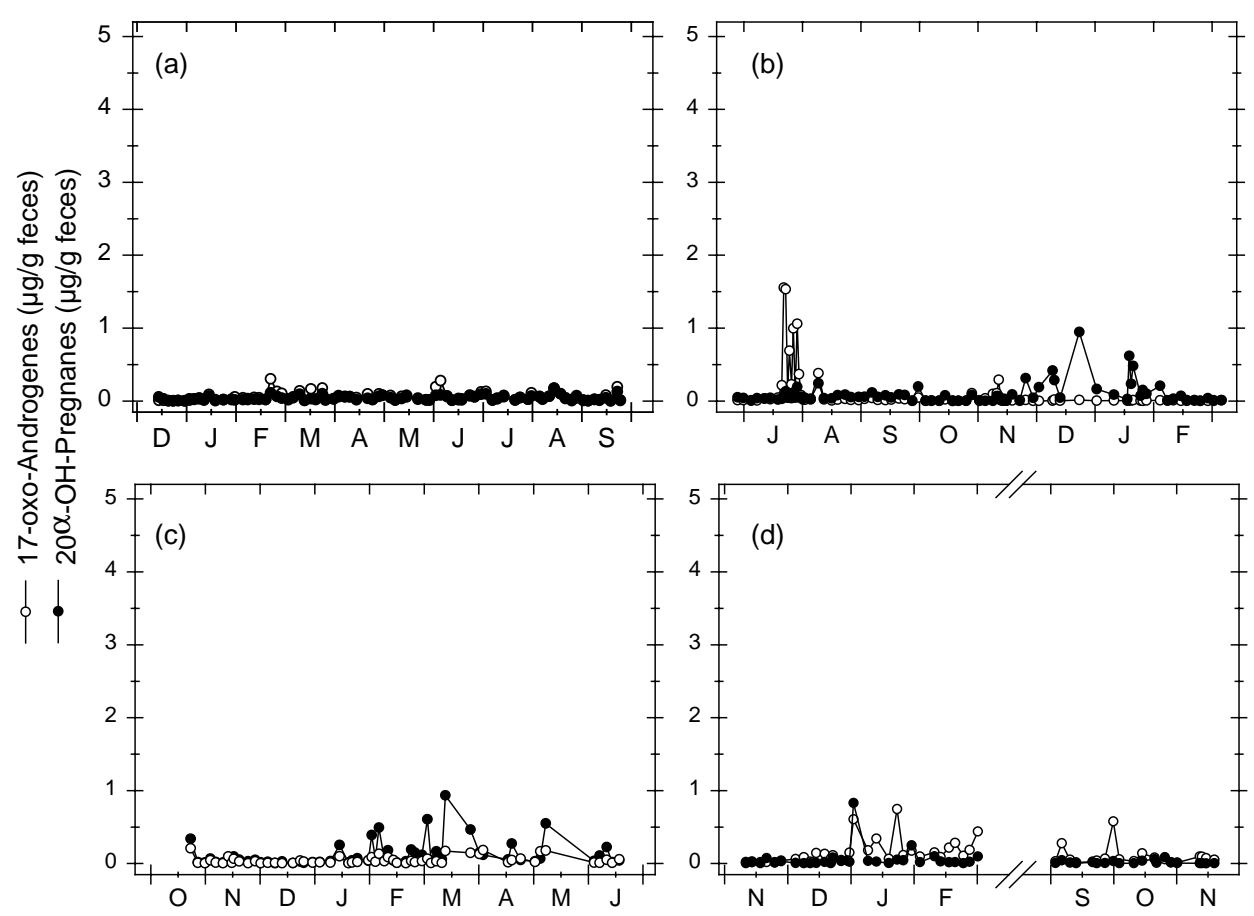

Fig. 4. Concentrations of 17-oxo-androgens and $20 \alpha-\mathrm{OH}-$ pregnanes in fecal samples of sun bears during periods of missing luteal activity. (a) 'Bao'; (b) 'Li'; (c) 'Kawan'; (d) 'Lotinka'.

made between a 'wet' season (around November to April) and a 'dry' season (around May to October) ( $t$-test, $t=4.96$, d.f. $=6, P=0.002)$. No significant difference was found in the number of cubs born during the dry season $(n=7)$ and the wet season $(n=11)$ (MannWhitney, $T=143, P=0.495$ ).

\subsection{Effects of PZP treatment}

Results of the PZP treatment are shown in Figs. 6 and 7. The animal 'Bärlein' (Fig. 6) received four PZP injections between autumn 1994 and beginning of 1996 (for details see Table 1). Two unsuccessful matings in the second year after PZP treatment were not associated with an increase in the fecal estrogen precursors. Elevated androgen levels during the three follicular phases that followed lasted for 30, 32, and 26 days, respectively. These three follicular phases thus were considerably longer than the 17-day-long follicular phase at the end of the sample collection period, which was followed by a subsequent luteal phase of 111 days.

Results obtained from the second PZP-treated sun bear ('Ours') diverged from the above (Fig. 7a). Fecal steroid levels in this female remained elevated for 17-oxo-androgens over a period of 10 months and indicated persistent follicular activity. Even the $20 \alpha-\mathrm{OH}$-pregnane concentrations were elevated for 5 of these months. These results were comparable to those of 'Anak' (Fig. 7b), who was not treated with PZP. 


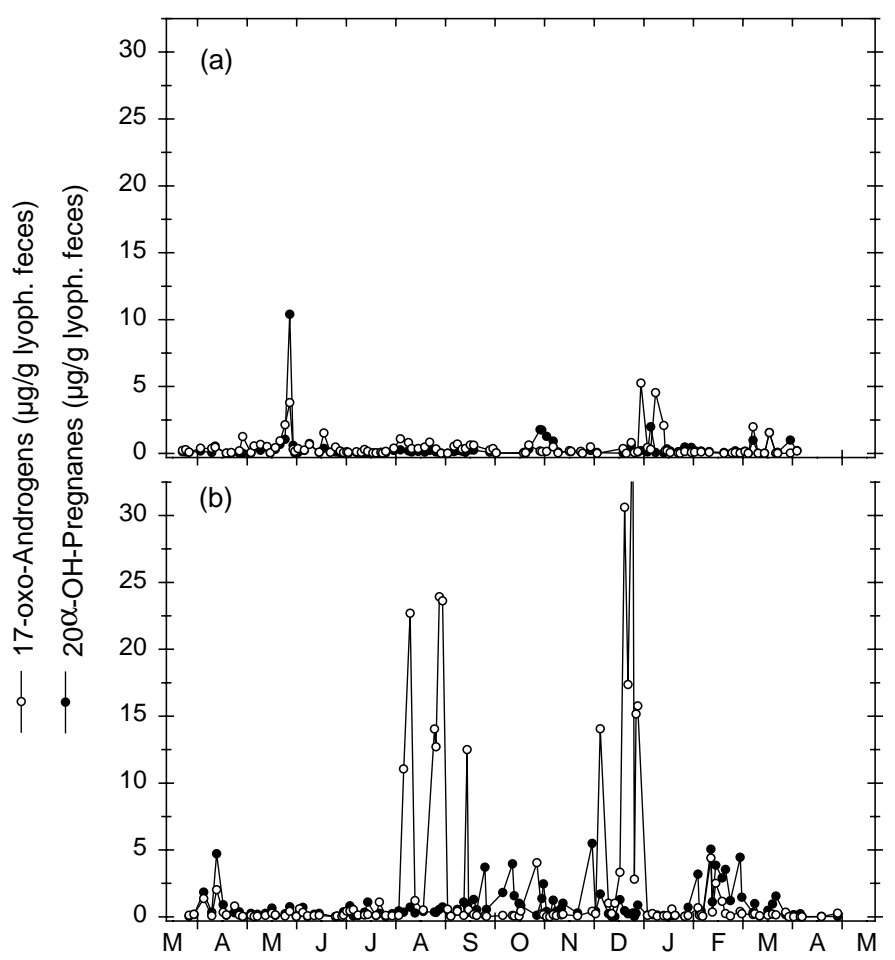

Fig. 5. Concentrations of 17-oxo-androgens and $20 \alpha-\mathrm{OH}$-pregnanes in lyophilized fecal samples of free-ranging sun bears. (a) 'Ucil'; (b) 'Ganja'.

\section{Discussion}

Results of our endocrine studies, and supplementary confirmatory data collected from the wild, demonstrate that the sun bear is a polyestrous, nonseasonal breeder. These findings correspond with analysis of studbook data [4]. This is different than the other bear species of the Northern hemisphere (American and Asiatic black bear, brown bear, polar bear, sloth bear and giant panda), which mate from spring to summer and birth mostly in early winter [1,2,9-17]. In the other tropical bear species, the spectacled bear, cubs are born between December and February, a couple of months before fruit production is at its highest, so that the cubs can feed on fruits $[18,19]$.

Our results disagree with Onuma and coworkers [20,21], who report a yearly seasonal rise in estrogen levels in captive sun bears in Sarawak, Malaysia, coinciding with inferred delivery during the wet season in December through January. However, collection of samples during their studies were infrequent (once every 2 weeks), and it is possible that rises in estrogen levels could have been missed. Even more important in this regard is that estrogen analysis, according to our results, does not seem to be a reliable indicator of the follicular phase. In addition, sun bear cubs in zoos and in the wild were born throughout the year [4]. Moreover, seasonality throughout the distribution range of the sun bear varies 


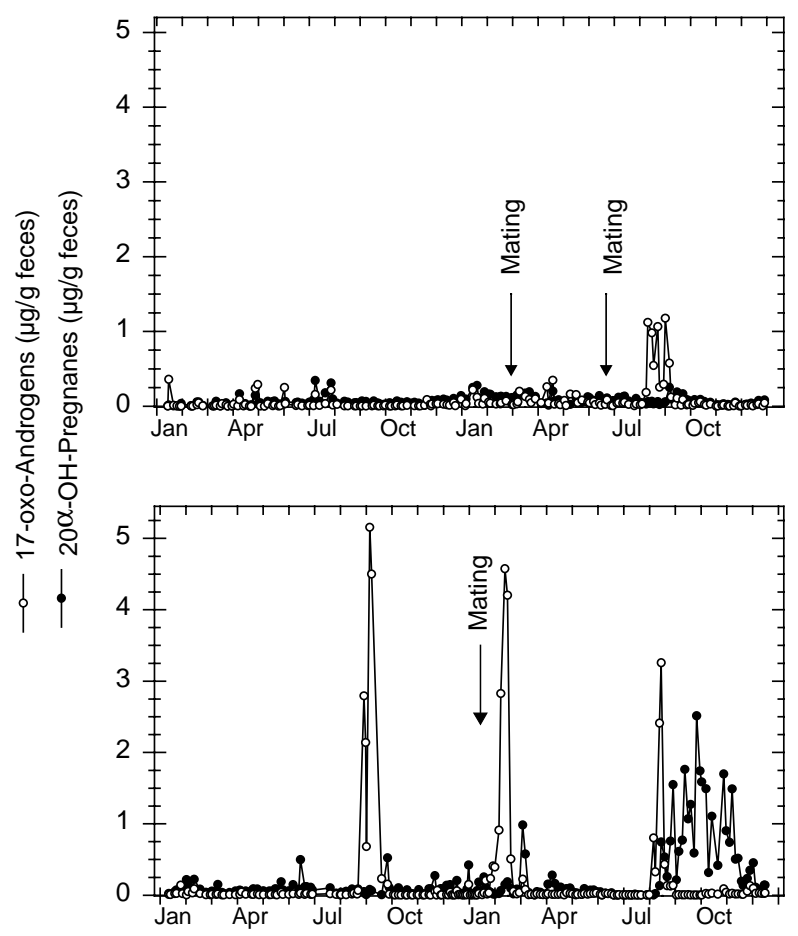

Fig. 6. Concentrations of 17-oxo-androgens and 20 $\alpha-\mathrm{OH}$-pregnanes in fecal samples in the sun bear 'Bärlein' during 4 years following PZP treatment.

significantly and can be unpredictable, from its western edge in Myanmar with large monsoons to its eastern edge in Kalimantan, where prolonged El Niño droughts occur [22]. Sun bear food availability in its natural habitat is not fluctuating in accordance to strict seasons; large-scale fluctuations in fruit production occur at supra-annual intervals of 2-10 years in large parts of Southeast Asia [22], whereas insect availability can remain stable throughout the year [23].

Interspecies comparison of fecal endocrine data from several animal species demonstrates the importance of testing several steroid assays for reproductive investigation [7]. Androgens, precursors of estrogens, were found to be reliable indicators of the follicular phase in our study, whereas pregnanediol was a good indicators of luteal function. In contrast to hormonal studies by Onuma and coworkers $[20,21]$ estradiol and progesterone assays were found to be unsuitable for the analysis of fecal hormones in sun bears. On the other hand, results by other authors $[12,24,25]$ show that estradiol and progesterone assays can be used for the analysis of fecal steroids in brown bears, whereas a pregnanediol assay was used for the analysis of urinary progesterone metabolites in the giant panda [26]. In other carnivore species, i.e. the domestic dog, luteal phases were monitored analyzing fecal progesterone metabolites $[27,28]$, whereas the pregnanediol assay used in our study on sun bears was found to be less suitable [28]. Additionally, in the dog, androgen metabolites are excreted into the feces during the follicular phase [27,29]. Progesterone and estrogen 


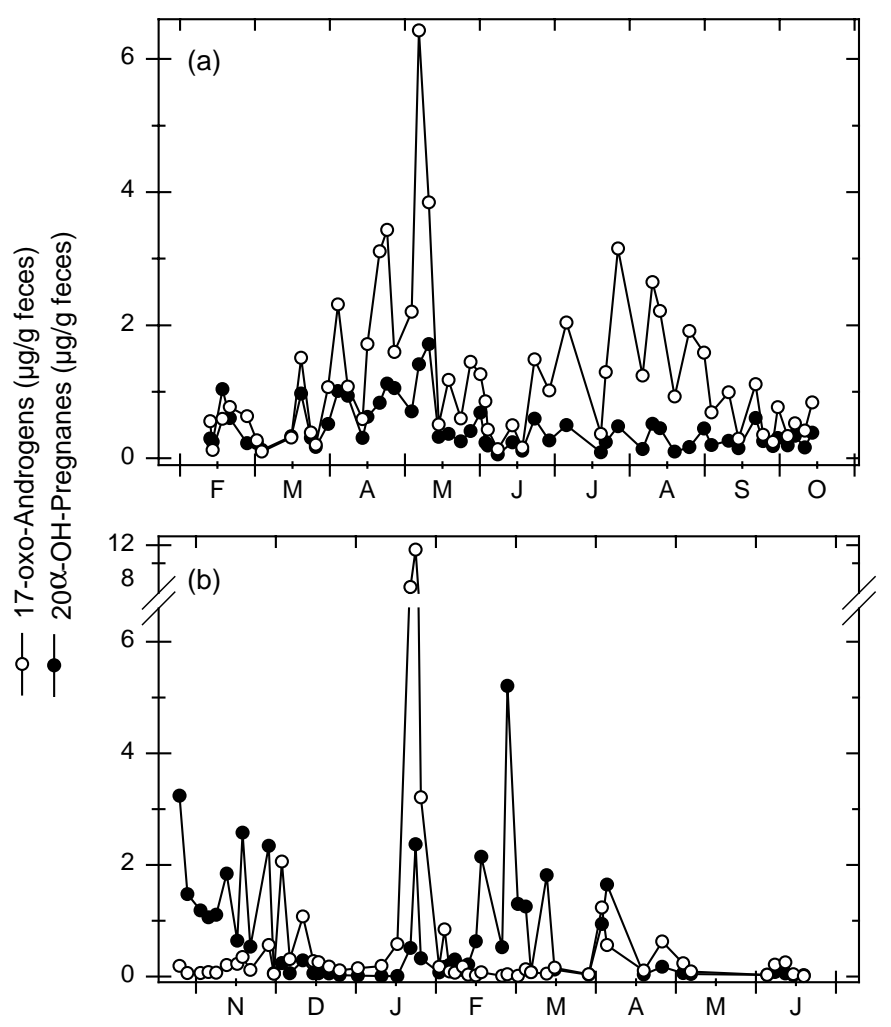

Fig. 7. Concentrations of 17-oxo-androgens and $20 \alpha-\mathrm{OH}$-pregnanes in fecal samples of sun bears during periods of erratic ovarian activity. (a) 'Ours'; (b) 'Anak'. The animal 'Ours' was treated with PZP prior to endocrine monitoring.

assays are also used for monitoring ovarian function in a wide range of exotic feline species [30,31]. In yet another species, the Indian rhinoceros fecal estrogens and androgens are indicators of the follicular phase and pregnanediol and 20-oxo-pregnanes are indicators of the luteal phase [8].

According to observations in captivity, pregnancy length in sun bears is 95-107 days [3-5]. Gestation length in other ursine species is more variable, e.g. 128-161 days in giant pandas, 150-272 in spectacled bears, 151-301 days in polar bears, and 190-260 days in brown bears. Most likely this variable length is due to different length of the embryonic diapause (delayed implantation), which is confirmed to occur in American and Asiatic black bears, brown bears, spectacled bears and polar bears, with implantation of the blastocyst occurring in November. Progesterone concentrations during diapause are low, and increase only gradually until implantation, which is characterized by a sharp increase and high progesterone levels until parturition [1,2,10-18,32-34]. Progesterone metabolites in the pregnant animal 'Bali' increased above threshold levels approximately one month after mating and decreased 2 weeks before parturition. Nonetheless, because variation in pregnancy length in sun bears is only moderate and its reproduction is nonseasonal, it is not 
assumed that this endocrine pattern is due to embryonic diapause. However, further research on the embryonic development in sun bears is needed to clarify this question.

Progesterone metabolites in pregnant and nonpregnant animals were comparable in our study. This is in agreement with studies on plasma progesterone in other bears species $[13,15,33,34]$, but contrasts the finding of fecal progesterone metabolites in the dog, in which pregnant animals excreted higher concentrations than nonpregnant animals [27]. The length of the luteal phase seems to be similar in pregnant and nonpregnant sun bears. The mean luteal phase length in this study was about 90 days; the interval from the beginning of the follicular to the beginning of the luteal phase was about 25 days. These numbers sum to $\sim 115$ days, comparable to the interbirth-interval of $126 \pm 9$ days observed in captive sun bears where cubs died after birth. Postpartum estrus in these animals occurred within 2-5 weeks after parturition [4].

Induced ovulation has been proposed to occur in other bear species [35] and was confirmed by laparoscopy to occur after mating in the American black bear [36]. It is possible that social contacts in sun bears act as stimuli to induce ovarian activity. However, as several complete estrous cycles consisting of follicular and luteal phases were observed in this study, the sun bear is not regarded as a classical induced ovulator in which the preovulatory LH surge is solely released by receipt of genital somatosensory stimuli during mating [37]. Possibly, sun bears could be compared with certain feline species. In these primarily induced ovulators, spontaneous ovulations have been observed occasionally in group housed females and the duration and magnitude of the LH surge are related to the amount of coital stimulation received [37]. In a study of ovulation-triggers in lions, one out of five study animals underwent spontaneous ovulation, whereas in four lionesses ovulation was induced by mounting [38].

Unexplained ovarian inactivity for periods of more than 8 months was observed in several animals in our study. This inactivity also occurred in animals, which had several normal estrous cycles prior to these inactive periods, as well as in an animal which was pregnant after such a period. A period of follicular activity in the animal 'Li' was not followed by a luteal phase and similar data were observed in one animal in the wild. No clear explanation has been found for these periods of ovarian inactivity. All captive females during this study were together with a male and had opportunities for social and sexual interactions. Thus, for sun bears it still remains to be studied to what extend ovulation is triggered by mating or other forms of social contact, or whether it is a combination of spontaneous and induced ovulation as is known to occur in several felid species $[30,31,38]$.

PZP is widely used for contraception in ungulate and carnivorous species [6,39]. In the majority of studies, reversibility of PZP immuno-contraception was tested by the occurrence of pregnancies. Only a few studies included monitoring of ovarian and endocrine function. Long-term treatment of feral mares demonstrated that immuno-contraception was reversible after PZP treatment for over $70 \%$ of mares treated for 1-5 consecutive years. However, immuno-contraception was not reversible in mares treated for 7 consecutive years [40]. Other studies, i.e. in bitches, rabbits, common marmosets and baboons, indicated that PZP treatment can be associated with a decline in ovarian hormone production and ovulation rates. The correlation of ovarian damage with PZP immunization depends on factors such as purity of the antigen, susceptibility, adjuvants and the presence of T- and B-cell epitopes [39]. 
Comparable to these studies, PZP treatment of sun bear could have caused altered ovarian function. Fecal steroid levels in one animal ('Ours') indicated the presence of persistent follicular and luteal activity, but this was also the case in a nontreated animal. The second PZP-treated animal ('Bärlein') had missing ovarian activity over an extended period. In this animal three periods of prolonged follicular activity were observed, before a normal estrous cycle occurred four years after PZP treatment. This animal died one year after endocrine analysis had ended; at post-mortem investigation macroscopically and microscopically normal ovaries were found (Göritz and Jewgenow, personal communication). As a consequence of these results in two animals in this study, a final recommendation whether and how this contraceptive method could be applied to sun bears is not possible. If this treatment is to be developed further, additional studies monitoring the effects of PZP on ovarian function are necessary.

In conclusion, monitoring of follicular and luteal phases in sun bears is possible using fecal steroid assays for 17-oxo-androgens and pregnanediol, respectively, whereas the more classical assays for estrogens and progesterone metabolites were unsuitable. Results demonstrate that the sun bear is a nonseasonal breeder, with follicular and luteal phases of 2 weeks and 3 months in lengths, respectively.

\section{Acknowledgements}

We thank the animal keepers at the zoos Basle (C.H.), Cologne (G.), Frankfurt (G.), Jihlava (C.Z.), Munster (G.), Romaneche (F.) for their conscientious collection of the fecal samples; Dr. O. Pagan (Basle), Dr. B. Matern (Frankfurt); Dr. P. Bradac (Jihlava), and Dr. Y. Chaduc (Romaneche) for their supervision of sample collection; Dr. E. Möstl for the preparation of antibodies and biotinylated labels; and Mrs. A. Aichinger and Mrs. E. Leitner for excellent technical assistance.

\section{References}

[1] Servheen C, Herrero S, Peyton B. Bears, status survey and conservation action plan. Gland, Switzerland: IUCN/SSC Bear and Polar Bear Specialist Group; 1999.

[2] Stirling I. Bears-majestic creatures of the wild. London: Harper Collins; 1993.

[3] Dathe H. A second generation birth of captive sun bears at East Berlin Zoo. Int Zoo Yearbook 1970; 10:79.

[4] Kolter L. Der Malaienbär. In: Gansloßer U, editor. Die Bären. Fürth, Germany: Filander Verlag; 2000. p. 235-46.

[5] McCusker JS. Breeding Malayan sun bears. Int Zoo Yearbook 1974;14:118-9.

[6] Kirkpatrick JF, Turner JW, Liu IKM, Fayrer-Hosken R. Applications of pig zona pellucida immunocontraception to wildlife fertility control. J Reprod Fertil Suppl 1996;50:183-9.

[7] Schwarzenberger F, Möstl E, Palme R, Bamberg E. Faecal steroid analysis for non-invasive monitoring of reproductive status in farm, wild and zoo animals. Anim Reprod Sci 1996;42:515-26.

[8] Schwarzenberger F, Rietschel W, Vahala J, Holeckova D, Thomas P, Maltzan J, et al. Fecal progesterone, estrogen, and androgen metabolites for noninvasive monitoring of reproductive function in the female Indian rhinoceros, Rhinoceros unicornis. Gen Comp Endocrinol 2000;119:300-7.

[9] Boone WR, Richardson ME, Greer JA. Breeding behavior of the American black bear Ursus americanus. Theriogenology 2003;60:289-97. 
[10] Dathe H. Beobachtungen zur Fortpflanzungsbiologie des Braunbären, Ursus arctos L. Der Zoologische Garten NF 1961;25:235-50.

[11] Dittrich L, Kronberger H. Biologisch-anatomische Untersuchungen über die Fortpflanzungsbiologie des Braunbären (Ursus arctos L.) und anderer Ursiden in Gefangenschaft. Zeitschrift für Säugetierkunde 1963;28:129-55.

[12] Göritz F, Hildebrandt T, Jewgenow K, Wagner N, Hermes R, Strauß G, et al. Transrectal ultrasonographic examination of the female urogenital tract in nonpregnant and pregnant captive bears (Ursidae). J Reprod Fertil Suppl 1997;51:303-12.

[13] Hellgren EC, Vaughan MR, Gwazdauskas FC, Williams B, Scanlon PF, Kirkpatrick RL. Endocrine and electrophoretic profiles during pregnancy and nonpregnancy in captive female black bears. Can J Zool 1990;69:892-8.

[14] Ramsay MA, Stirling I. Reproductive biology and ecology of female polar bears (Ursus maritimus). J Zool (Lond) 1988;214:601-34.

[15] Tsubota T, Howell-Skalla L, Boone WR, Garshelis DL, Bahr JM. Serum progesterone, oestradiol, luteinizing hormone and prolactin profiles in the female black bear (Ursus americanus). Anim Reprod Sci 1998;53:107-18.

[16] Tsubota T, Kanagawa H. Morphological characteristics of the ovary, uterus and embryo during delayed implantation period in the Hokkaido Brown Bear (Ursus arctos yesoensis). J Reprod Dev 1993;39:325-31.

[17] Zhu X, Lindburg DG, Pan W, Forney KA, Wang D. The reproductive strategy of giant pandas (Ailuropoda melanoleuca): infant growth and development and mother-infant relationships. J Zool (Lond) 2001;253:141-55.

[18] Kolter L. Der Brillenbär. In: Gansloßer U, editor. Die Bären. Fürth, Germany: Filander Verlag; 2002. p. $47-258$.

[19] Peyton B. Spectacled bear conservation action plan. In: Servheen C, Herrero S, Peyton B, editors. Bears, status survey and conservation action plan. Gland, Switzerland: IUCN; 1999. p. 157-98.

[20] Onuma M, Suzuki M, Ohtaishi N. Reproductive pattern of the sun bear (Helarctos malayanus) in Sarawak, Malaysia. Jpn J Vet Med Sci 2001;63:293-7.

[21] Onuma M, Suzuki M, Uchida E, Niiyama M, Ohtaishi N. Annual changes in fecal estradiol-17beta concentrations of the sun bear (Helarctos malayanus) in Sarawak, Malaysia. Jpn J Vet Med Sci 2002;64:309-13.

[22] Curran LM, Trigg SN, McDonald AK, Astiani D, Hardiono YM, Siregar P, et al. Lowland forest loss in protected areas of Indonesian Borneo. Science 2004;303:1000-3.

[23] Fogden MPL. The seasonality and population dynamics of equatorial forest birds in Sarawak. Ibis $1972 ; 114: 307-41$.

[24] Göritz F, Quest M, Hildebrandt T, Meyer HHD, Kolter L, Elger W, et al. Control of reproduction with antiprogestin and oestrogens in captive bears. J Reprod Fertil Suppl 2001;57:249-54.

[25] Ishikawa A, Kikuchi S, Katagiri S, Sakamoto H, Takahashi Y. Efficiency of fecal steroid hormone measurement for assessing reproductive function in the Hokkaido brown bear (Ursus arctos yesoensis). Jpn J Vet Res 2002;50:17-27.

[26] Czekala N, McGeehan L, Steinman K, Xuebing L, Gual-Sil F. Endocrine monitoring and its application to the management of the giant panda. Zoo Biol 2003;22:389-400.

[27] Gudermuth DF, Concannon PW, Daels PF, Lasley BL. Pregnancy-specific elevations in fecal concentrations of estradiol, testosterone and progesterone in the domestic dog (Canis familiaris). Theriogenology 1998;50:237-48.

[28] Möstl E, Brunner I. Comparison of different progestagen assays for measuring progesterone metabolites in faeces of the bitch. J Vet Med A 1997;44:573-8.

[29] Möstl E, Brunner I. Increase of androgen metabolites of the bitch excreted via faeces during oestrus. Zeitschrift für Säugetierkunde (Int J Mam Biol Suppl II) 1997;62:160-3.

[30] Brown JL, Graham LH, Wielebnowski N, Swanson WF, Wildt DE, Howard JG. Understanding the basic reproductive biology of wild felids by monitoring of faecal steroids. J Reprod Fertil Suppl 2001;57:71-82.

[31] Moreira N, Monteiro-Filho ELA, Moraes W, Swanson WF, Graham LH, Pasquali OL, et al. Reproductive steroid hormones and ovarian activity in felids of the Leopardus genus. Zoo Biol 2001;20:103-16.

[32] Lengwinat T, Quest M, Göritz F, Tscherner W, Kolter L. Zur Embryonalruhe des Brillenbären (Tremarctos ornatus Cuvier, 1825). Der Zoologische Garten NF 2001;71:137-46. 
[33] Palmer SS, Nelson RA, Ramsay MA, Stirling I, Bahr JM. Annual changes in serum sex steroids in male and female black (Ursus americanus) and polar (Ursus maritimus) bears. Biol Reprod 1988;38:1044-50.

[34] Derocher AE, Stirling I, Andriashek D. Pregnancy rates and serum progesterone levels of polar bears in western Hudson Bay. Can J Zool 1992;70:561-6.

[35] Boone WR, Catlin JC, Casey KJ, Boone ET, Dye PS, Schuett RJ, et al. Bears as induced ovulators. Ursus 1998;10:503-5.

[36] Schulz LC, Nelson RA, Pyter LM, Bahr JM. Induction of pseudopregnancy in the American Black Bear (Ursus americanus). J Exp Zool 2003;298A:162-6.

[37] Bakker J, Baum MJ. Neuroendocrine regulation of GnRH release in induced ovulators. Front Neuroendocrinol 2000;21:220-62.

[38] Schramm RD, Briggs MB, Reeves JJ. Spontaneous and induced ovulation in the Lion (Panthera leo). Zoo Biol 1994;13:301-7.

[39] Barber MR, Fayrer-Hosken RA. Possible mechanisms of mammalian immunocontraception. J Reprod Immunol 2000;46:103-24.

[40] Kirkpatrick JF, Turner JW. Reversibility of action and safety during pregnancy of immunization against porcine zona pellucida in wild mares (Equus caballus). Reprod Suppl 2000;60:197-202. 